\title{
How Can the Error Term Be Correlated with the Explanatory Variables on the R.H.S. of a Model?
}

\author{
Yunyun Lv \\ Department of Economics, Kansas State University, Manhattan, KS, USA \\ Email: yunyun@ksu.edu, feifei_614@hotmail.com
}

How to cite this paper: Lv, Y.Y. (2017) How Can the Error Term Be Correlated with the Explanatory Variables on the R.H.S. of a Model? Theoretical Economics Letters, 7, 448-453.

https://doi.org/10.4236/tel.2017.73033

Received: February 9, 2017

Accepted: April 10, 2017

Published: April 13, 2017

Copyright $\odot 2017$ by author and Scientific Research Publishing Inc. This work is licensed under the Creative Commons Attribution International License (CC BY 4.0).

http://creativecommons.org/licenses/by/4.0/

\begin{abstract}
Since macroeconomic research cannot be replicated, most studies may claim their conclusive research findings solely based on the statistical significance of the estimated coefficients. In this framework, we use a small simulation experiment to show that if variables affect the economy through different horizons, even though the error term is not correlated with both the explanatory variables on the right-hand side (R.H.S.) of a model and the dependent variable from a traditional view, the estimated coefficients can still be biased. The evidence provided by this paper may explain the refutation and controversy results in the modern research.
\end{abstract}

\section{Keywords}

Cointegration in the Longer Horizons, Simulation

\section{Introduction}

Published research findings of the relationships among variables are sometimes refuted by subsequent evidence. For instance, Hamilton (1983) [1] shows that oil shocks may be a contributing factor in some of the recessions before 1972. In order to explore the asymmetric effects of oil price on output, Mork (1989) [2] estimates separate coefficients for oil price increase and decrease. Additionally, Hooker (1996) [3] provides evidence that the predictive power of oil shocks on macro variables diminish as the sample is updated. Examples also include that the traditional view in the literature until 2003 espouses that the real price of oil responses to the oil supply shocks more than the oil demand shocks, whereas Kilian (2009a) [4] provides evidence that the real price of oil responses to the oil supply shocks less than the oil demand shocks. The sectoral shift hypothesis discusses that it is possible for large oil price changes in either direction to potential to hurt output. The instability of the empirical relation between oil price 
and output incurs a debate over whether the oil-price-GDP relationship still exists or not. Refutation and controversy are seen in the oil price literature as the data are updated.

Couple studies discuss the increasing concern that the findings claimed by the vast majority of published research are false. Loannidis (2005a [5], 2005b [6]) point out that the poor agreement of subsequent research with initial findings in the most influential medical journals published between 1990 and 2003 and provide some concerns which may cause most published research findings in a scientific field false under reasonable assumptions. Romer (2016) [7] questions the opaque assumptions and the incredible identifications, especially criticizing the "imaginary shocks" in the "post-real" macroeconomic literature. In this paper, I use the assumption that variables affect the economy through various time spans to examine how this assumption affects the estimated coefficients of the macroeconomic models and some corollaries thereof through a different perspective from the traditional view.

According to the complication of the economy, macroeconomic research cannot be replicated (lack of confirmation from a scientific view). The research discoveries are a consequence of the convenient strategy by simplification. We select couple key variables in the near term by statistical significance, typically for a p-value less than 0.05 and use these variables to claim the conclusive research findings for all horizons. However, under my new assumption, variables may be cointegrated through different horizons. For instance, from the Unbiased Forward Rate(UFR) hypothesis which posits the long-run equilibrium between forward and spot exchange rates on the sixth page of Enders (2014) [8], we can assume that forward value of $Y$ can have a long-run equilibrium with current value of $f$ :

$$
Y_{t+s}=\alpha_{0}+\alpha_{1} f_{t}+Z_{t+s}
$$

It may exist that both $Y_{t+s}$ and $f_{t}$ are $I(1)$ and $Z_{t+s}$ is $I(0)$. If we consider $f_{t}$ as the error term, some variable $Y_{t+s}$ may be correlated with the error term $f_{t}$ multiple-step ahead. In other words, under my assumption that variables can affect the economy through different horizons, even though the estimated error term is not correlated with the explanatory variables on the right-hand side (R.H.S.) of a model in the near term from a conventional perspective, we cannot assert that they must not be correlated through a longer horizon, which may lead to biased estimates of coefficients.

The innovation of this paper is that I show the influence of the estimated coefficients when the error term is correlated with the explanatory variables through a long horizon rather than the short horizons by simulation. According to my results, the traditional model may not be sufficient to resolve the real coefficients of relationships among variables when the error term is correlated with variables on the R.H.S. of the model through the long horizons. Hence, the misinterpretation may exist in the literature.

The remainder of the paper is organized as follows. Section 2 constructs the simulation experiment and analyzes the results. Concluding comments and di- 
rections for future research are given in Section 3.

\section{Simulation}

In this section, I present the details of our evaluations via simulation. The series of simulation results I carried out reflect in part the major aim of the possibility that the long-horizon relationships of the error term and the explanatory variables can be ignored by the traditional models.

If the variables on the right-hand side of a model, denoted as $x_{t}$, are not correlated with residuals $e_{t}$, but correlated with the lagged residuals $e_{t-1}$, these variables can take the contributions of factors in the lagged residuals as part of their own coefficients. To verify that, I impose some hypotheses as following:

- Hypothesis 1 . The generated exogenous structural innovations are independent identically normal distributed (i.i.d.).

- Hypothesis 2. Variables can be cointegrated in the long horizons, which implies that different types of shocks can affect the same variable through different horizons, or the same type of shocks may affect different variables through different horizons.

First, I generate three types of shocks $u_{1, t}, u_{2, t}, u_{3, t}$, while $u_{1, t}, u_{2, t}$, $u_{3, t} \sim N(0,1)$. Then, I assume that $u_{1, t}$ and $u_{2, t-1}$ affect $x_{t}$ through different horizons, whereas $u_{2, t-1}$ affects $x_{t}$ and $e_{t-1}$ through different horizons. To be specific, I assume that variable $x_{t}$ and residuals $e_{t}$ take the form of:

$$
\begin{aligned}
& x_{t}=0.1 \times u_{1, t}+0.5 \times u_{2, t-1} \\
& e_{t}=0.5 \times u_{2, t}+0.1 \times u_{3, t-1}
\end{aligned}
$$

To exemplify, I begin by drawing 100 normally distributed random values for each type of shocks ${ }^{1}$. Then, I compute variable $x_{t}$ and residuals $e_{t}$ by Equation (1) and Equation (2) and estimate the regressions. After running the above process 10,000 times, I calculate the average estimations of the relationship between $x_{t}$ and $e_{t}$ :

$$
\begin{gathered}
x_{t}=\alpha_{1}+\beta_{1} e_{t}+v_{1, t} \\
x_{t}=\alpha_{2}+\beta_{2} e_{t-1}+v_{2, t}
\end{gathered}
$$

where letting $\hat{\beta}_{1}$ and $\hat{\beta}_{2}$ be the Equation (3) \& Equation (4) mean estimates of $\beta_{1}$ and $\beta_{2}$, respectively. In this paper, I use ${ }^{* * *}$ on the right side of $\mathrm{p}$-value to indicate the $0.1 \%$ level of significance of the coefficients. According to the results in Table 1, I show that $x_{t}$ and $e_{t}$ are not correlated from a standard view, but $x_{t}$ and $e_{t-1}$ is statistically significantly correlated at a $0.1 \%$ level like the possible relationships of variables and the error term in a traditional model. This assumption is reasonable because we may not include all key variables in the model, there may be some vital variables concealed in the residuals which are correlated with both dependent variables and explanatory variables through long time scales.

Then I assume $y_{t}$ in Equation (5):

${ }^{1}$ I run all programs of this paper by $\mathrm{R}$. 
Table 1. Estimations when explanatory variables are correlated with error term one-step ahead.

\begin{tabular}{ccccc}
\hline & $\hat{\beta}$ & $t$-value & $p$-value \\
\hline$\hat{\beta}_{1}$ & -0.01 & -0.10 & 0.50 & \\
$\hat{\beta}_{2}$ & 0.96 & 34.48 & $4.67 \mathrm{E}-43$ & $* * *$ \\
\hline
\end{tabular}

Table 2. Estimations of the model with explanatory variables and error term at the same horizon.

\begin{tabular}{ccccc}
\hline & $\hat{\beta}$ & $t$-value & $p$-value & \\
\hline$\hat{\beta}_{3}$ & 0.78 & 29.59 & $3.27 \mathrm{E}-33$ & $* * *$ \\
$\hat{\beta}_{4}$ & -0.0009 & -0.03 & 0.50 & \\
\hline
\end{tabular}

Table 3. Estimations of the model with explanatory variables and error term from different horizons.

\begin{tabular}{ccccc}
\hline & $\hat{\beta}$ & t-value & p-value & \\
\hline$\hat{\beta}_{5}$ & 0.21 & 2.78 & 0.05 & \\
$\hat{\beta}_{6}$ & 0.60 & 8.05 & $5.45 \mathrm{E}-08$ & $* * *$ \\
\hline
\end{tabular}

$$
y_{t}=0.2 \times x_{t}+0.6 \times e_{t-1}+0.1 \times u_{3, t-5}
$$

Our 10,000-time simulation mean results of the following form are in Table 2.

$$
y_{t}=\alpha_{3}+\beta_{3} x_{t}+\beta_{4} e_{t}+v_{3, t}
$$

Comparing the real coefficients I impose in Equation (5) with the estimated results in Table 2, the estimated coefficients of $x_{t}$ and $e_{t}$ are biased. The estimated coefficient of $x_{t}$ is 0.78 , which is almost equal to 0.2 plus 0.6 , indicating that $x_{t}$ takes the effects of $e_{t-1}$ to pretend as its own coefficient. The part which contains the effect of $u_{3, t-1}$ in $e_{t-1}$ on $y_{t}$ is still concealed in the error term.

However, our 10,000-time simulation mean results of Equation (7) are near the real coefficients I set in Equation (5):

$$
y_{t}=\alpha_{4}+\beta_{5} x_{t}+\beta_{6} e_{t-1}+v_{4, t}
$$

In Table 3, when we substitute $e_{t}$ by $e_{t-1}$, the estimated coefficients are almost unbiased. Thus, if there are factors in the error terms which are correlated with the dependent variable and the explanatory variables on the R.H.S. over long horizons, we need to include these factors corresponding to their horizons, respectively. Otherwise, it will be concealed in $v_{3, t}$ in Equation (6) and the estimated coefficients of variables may be biased. These key variables selected in the near term in the model may take the coefficients of the omitted variables in the error term as their own coefficients.

To sum up, the above simulation results suggest that one needs to be cautious when interpreting the results of regressions. When the fundamental assumption of macroeconomics has been changed, the estimated coefficients of the traditional methods may be biased. 


\section{Conclusions}

Under the assumption that the variables may affect the economy through different horizons, this paper uses simulations to prove the possibility that the error term can be correlated with both explanatory variables and the dependent variables at the same time through longer horizons even though they are not correlated in the near term through a traditional view. Thus, the estimated coefficients of some traditional models may be biased under my new assumption. Moreover, I argue that it may be misleading to emphasize the statistically significant findings because some variables in the model may just take the contributions of the omitted variables concealed in the error term. The policy intuition of this paper is that the long-term economic problems cannot be fixed with shortterm interventions.

A potential criticism of the approach I implement is that I generate shocks by assuming that these exogenous structural innovations are i.i.d. Likewise, I generate several random shocks from the same distribution. However, the fluctuations of the real economic time series may not be from random shocks, but from shocks controlled by the information over different horizons. Additionally, these shocks may be correlated with each other through different horizons. Since my primary focus is to document the change in the estimated coefficients when shocks affect the economy through different horizons, the property of shocks may not affect my results that much. I do not think that this limitation is overly problematic. Nonetheless, the real economic activities are much more complex than my oversimplified simulation experiment. I am only interested in providing the possibility of how my assumption may affect the estimated coefficients of macroeconomic models, as opposed to claiming that my assumption reflects the mere fact of the economy in this paper.

Some concerns for future research are as followings:

First, the biased coefficients may be useful for forecasting since the relationships among variables in the economy were relatively stable. If the economy is not in a recession, the stable relationships among variables may lead to a good forecasting performance even without cause relationships. Nevertheless, we need to be as careful as possible to use the estimated coefficients of a linear model like OLS to explain the relationship among variables because part of the coefficients may be from the outside variables in the error term.

Second, some variables which play small roles when adopting a short-run perspective may affect the economy strongly in the long-time horizon, so we may need to select macroeconomic variables specific to the horizon.

Third, it is possible that the estimated coefficients of some variables in the model are affected by the omitted variables and the estimated magnitudes may change as the sum effect of the omitted variables changes. However, some vital variables may have the ability to associated with enough omitted variables to follow the pattern of their fluctuations no matter how the background of the economy changes. The estimated coefficients of these vital variables in the model are relatively stable even though they may be biased. 
Overall, if we change the assumption, the conclusions inferred from the biased coefficients of traditional models are by no means settled issues. It remains possible for a skeptic to maintain some dominant views of existing studies which are derived from the biased coefficients. These concerns are beyond the scope of this paper and needed to be further studied.

\section{References}

[1] Hamilton, J.D. (1983) Oil and the Macroeconomy Since World War II. The Journal of Political Economy, 91, 228-248. https://doi.org/10.1086/261140

[2] Mork, K.A. (1989) Oil and the Macroeconomy When Prices Go up and down: An Extension of Hamilton's Results. Journal of Political Economy, 97, 740-744. https://doi.org/10.1086/261625

[3] Hooker, M.A. (1996) What Happened to the Oil Price-Macroeconomy Relationship? Journal of Monetary Economics, 38, 195-213.

[4] Kilian, L. (2009) Not All Oil Price Shocks Are Alike: Disentangling Demand and Supply Shocks in the Crude Oil Market. American Economic Review, 99, 10531069. https://doi.org/10.1257/aer.99.3.1053

[5] Ioannidis, J.P. (2005) Contradicted and Initially Stronger Effects in Highly Cited Clinical Research. JAMA, 294, 218-228. https://doi.org/10.1001/jama.294.2.218

[6] Ioannidis, J.P.A. (2005) Why Most Published Research Findings Are False. PLoS Medicine, 2, e124.

https://doi.org/10.1371/journal.pmed.0020124

[7] Romer, P. (2016) The Trouble with Macroeconomics. The American Economist, forthcoming.

[8] Enders, W. (2014) Applied Econometric Time Series. 4th Edition. John Wiley, New York.

Submit or recommend next manuscript to SCIRP and we will provide best service for you:

Accepting pre-submission inquiries through Email, Facebook, LinkedIn, Twitter, etc. A wide selection of journals (inclusive of 9 subjects, more than 200 journals) Providing 24-hour high-quality service User-friendly online submission system Fair and swift peer-review system Efficient typesetting and proofreading procedure Display of the result of downloads and visits, as well as the number of cited articles Maximum dissemination of your research work

Submit your manuscript at: http://papersubmission.scirp.org/

Or contact tel@scirp.org 